\title{
Recruitment and Selection and Their Effect in Achieving the Institutional Excellence
}

\author{
Azzam Abou-Moghli ${ }^{1}$ \\ ${ }^{1}$ Department of Business Administration, Applied Science Private University, Amman, Jordan \\ Correspondence: Azzam Abou-Moghli, Department of Business Administration, Applied Science Private \\ University, Amman, Jordan. E-mail: a_aboumoghli@asu.edu.jo
}

Received: January 17, 2015

Accepted: January 31, $2015 \quad$ Online Published: February 25, 2015

doi:10.5539/ibr.v8n3p156

URL: http://dx.doi.org/10.5539/ibr.v8n3p156

\begin{abstract}
This study aimed at testing the effect of recruitment and selection functions in achieving the institutional excellence. To achieve this aim, the researcher developed a questionnaire and distributed it to a random sample representing the study population, which consisted of the private schools in Amman, Capital of Jordan. The descriptive statistics as well as the regression analyses were used to analyze the primary data. The study concluded many findings most importantly the existence of a statistically significant effect of recruitment and selection functions in achieving the institutional excellence. The study recommended placing high importance on recruitment and selection functions, including their requirements of personal abilities and tendencies tests. This is because recruiting competent individuals contribute to improving the performance level and achieving the institutional excellence.
\end{abstract}

Keywords: recruitment, selection, institutional excellence, private schools

\section{Introduction}

Attention to the human element became an unavoidable choice for any organization, because organizations realized that behind each and every achievement and development there is a human element. Therefore, organizations had to attract and select the best of the human resources that are capable to achieve the organization vision and objectives. Staffing is considered one of the most important functions that the human resources management should accomplish with utmost efficiency and effectiveness. Based on its success in this track, the other functions in the organization can be defined and determined, whether production, marketing, financial or development functions. This is particularly important in organizations where human resources management occupies a clear position in the organization structure. The staffing process is integrated with achieving a number of activities that include recruitment and selection (DeNisi \& Griffin, 2001; Collins \& Clark, 2003; Dissler, 2003; DeCenzo \& Robbin, 2005).

Recruitment and selection functions go even beyond the border of the internal environment of the organization to the external one, as the proper recruitment and selecting functions contribute to the requirements of achieving the institutional excellence (Al-Heeti, 2003).

A deliberate study of the literature relevant to the human resources management indicated that the recruitment and selection functions are important and useful in contributing to achieve the institutional excellence requirements. Nonetheless, there is a scarcity, as far the knowledge of the researcher goes, in the empirical studies that test the effect of the recruitment and selection functions in achieving the institutional excellence in private schools. Therefore, research in the effect of recruitment and selection functions in achieving the institutional excellence is one of the most important rationales of the current study.

\section{Literature Review}

\subsection{Recruitment}

Recruitment function includes obtaining the required human resources to ensure the continued functioning of the organization. This includes searching for proper, qualified individuals to work within the organization, who are expected to apply for jobs in the organization as a result of the existence of current vacancies, or expectancy of such vacancies in the near future (DeNisi \& Griffin, 2001). Al-Salem and Al-Saleh, (2002) indicated that recruitment is the search for right people to fill the vacancies in the workplace, encourage and attract them, and 
select the best of them. According to Hulin \& Hachiya (1985), the objective of recruitment is to supply a pool of possible candidates from which the organization can choose the required quantity in harmony with job requirements. Steel \& Ovalle II (1984) state that recruitment is the process of attracting candidates who may provide a contribution to the specific organization. Further Steel \& Ovalle II (1984) refer to attraction as the positive interaction between possible candidates and the values and information about an organization. According to Schervish (1983) failure to recruit candidates with suitable competencies will lead the organization to failure or, at least, inhibit growth. Hassan (2009) concluded that there is an impact of recruiting and selecting on realizing the competitive advantage of both cost and innovation.

\subsection{Selection}

Selection function represents the natural expansion of the recruitment function to attract the right workforce. The selection function implies the preference among the applicants to occupy the vacant job in terms of their suitability to the job. The selection function is vitally important due to the individual differences among individuals in terms of readiness, abilities and tendencies. This is also due to the differences among the jobs in their requirements, and the mental and physical properties that such jobs require (Abdul Baqi, 2001). The selection function could be defined as "the process through which the job applications are examined to ensure choosing those who meet the job specifications and requirement; interviewing the applicants, and eventually appointing them" (Al-Salem, 2002).

According to Campion, (1991) Selecting is the process regarding the fit between the candidates and the job post. O'Reilly et al. (1991) found that levels of job satisfaction will increase if there is a good fit between candidate's personality and the job post. O'Reilly et al. (1991) additionally reported that candidates who accept a job in an organization and who cannot adopt the value system of the organization do not usually stay long nor they are productive workers. Moreover, Thompson et al. (2006) states that "a happy worker is a productive worker". El-Jareeri found that there is an impact of selection strategy in achieving competitive advantage. It appears that selecting the right candidates and placing them in the right job is important, and may contribute to the success as well as the excellence of organizations.

\subsection{Institutional Excellence}

Excellence is a way of life which may occur in a small or large organization, whether governmental or non-governmental, which provides a service or manufactures a commodity (Ajaif, 2008). Thus, it is an intellectual style and administrative philosophy based on a method linked with the way of achieving tangible results of the organization to produce true balance in satisfying the needs of all the parties, whether they were stakeholders or the community at large, within the framework of a culture of continuous learning, innovation and improvement (Al-Sayyid, 2007). Furthermore, excellence is also a comprehensive, and undividable concept, which means that an organization's excellence cannot be imagined in a certain domain, where performance on other domains is collapsing. Balance and overlapping are basic characteristics of excellence within the different departments and divisions of the organization. It contains two dimensions of the modern management axes; one is that the actual management end is seeking to achieve excellence, and the other is that whatever the management issues of works and decisions, and the systems and activities it manages, are excellence characterized. The two dimensions are integrated; one cannot be achieved without the other (Al-Salmi, 2001). European Foundation for Quality Management (EFQM), indicated that excellence refers to the skill in the organization performance and achieving the results based on a number of basic practices that include: focus on production, customer care, leadership, target stability, operation management, individuals' participation, continuous improvement and innovation, mutual benefit among the companies, joint social responsibility, and realizing benefits of the stakeholders in a balanced manner (Aldallal, 2005). Accordingly, excellence is the organization's exploitation of the available opportunities within the framework of the effective strategic planning; commitment to the perception of a common vision controlled by the clarity of the purpose, and sufficiency of resources and concern for performance. Zairi (2005) assures that the excellence in organizations is the one focusing on opportunities rather than on problems. Jawad and Al-Khraisheh (2008) indicate that excellence is a specific process of practices that include self-evaluation to improve the effectiveness of the organization, its competitiveness position, work harmony in the organization, participation of all the workers throughout all departments of the organization to work together, through understanding all the activities, removal of all the mistakes, and improving the process toward achieving the excellence.

\section{Hypothesis Formulation}

Based on the related literatures in human resources management that were available to the researcher, and in the light of the topics contained in the introduction and literature review, the following hypotheses were formulated: 


\subsection{Main Hypothesis HO1}

There is no statistically significant effect of recruitment and selection functions in achieving the institutional excellence at $(\alpha \leq 0.05)$ significance level. Of this main hypothesis, the following sub-hypotheses were derived:

\subsubsection{The First Sub-Hypothesis H01-1}

There is no statistically significant effect of recruitment function in achieving the institutional excellence at ( $\alpha \leq$ $0.05)$ significance level.

\subsubsection{The Second Sub-Hypothesis H01-2}

There is no statistically significant effect of selection function in achieving the institutional excellence, at ( $\alpha \leq$ $0.05)$ significance level.

\section{Methodology}

The researcher used the descriptive analytic method, for the purpose of data collection and analysis, as well as testing the hypotheses; as this method depends on the study of the facts or the phenomenon. Therefore, the descriptive analytic method is the appropriate method for the current research; since the method is defined as the one seeking to approach the detailed knowledge of the components of a problem or phenomenon, for the aim of reaching a better and more accurate understanding, (Al-Nu'aimi et al., 2009; Hair et al., 2006), which applies to the nature of the present research.

\subsection{Study Population and Sample}

The study population consisted of all the principals and heads of the departments in the private schools $(n=46)$ located within the Jordanian Capital, Amman, with schools having only 500 or more students. The researcher conducted a survey on all the study population which included all the principals and heads of the departments working in the private schools within the limits of Amman, Capital of Jordan, with each school having 500 students or more, brining about the total number of the surveyed to 248 individuals.

Two hundred forty eight (248) questionnaires were distributed to the study sample, of which 226 were returned $(91.4 \%)$. The questionnaires were tested to verify their validity for statistical analysis, and 15 were excluded due to invalidity for such analysis, as they lacked the statistical analysis requirement. As a result, the total number of the valid questionnaires valid for statistical analysis was 211 questionnaires $(89.1 \%)$ of the total number distributed to the sample.

The collected data through the questionnaire, which was adapted by the researcher, based on the available literature and previous studies. The questionnaire consisted of three sections: demographic variables section, staffing variables through two dimensions (recruitment and selection functions) section, and the institutional excellence section. The range of responses was between 1 and 5, based on the five-point likert scale.

\subsection{Statistical Processing}

To perform the research statistical analysis, the researcher utilized a computer software, the statistical package for social sciences (SPSS), for windows version 17; through this package, the researcher used the following statistical methods:

Cronbach Alpha Coefficient to verify the reliability or internal consistency of the used scale.

Frequencies and percentages to describe the demographic variables of the study sample.

Means (M's) and standard deviations (SD's) for the purpose of identifying the relative importance of items of the study dimensions.

Simple and multiple regression analysis.

\subsection{Validity and Reliability of the Research Instrument (Questionnaire)}

\subsubsection{Apparent Validity}

The questionnaire was presented to a group of five academic arbitrators, who were specialized in business administration. The researcher took into account adhering to their views and carrying out the deletion or amendment in the light of their suggestions. Thus the questionnaire was finally approved in the shape herein below described.

\subsubsection{Reliability}

The researcher applied Cronbach Alpha coefficient to test the research instrument reliability. Even though the measurement rules in the value to be achieved is not specified, yet obtaining Alpha $>0.60$ is considered, from 
the applied perspective of the administrative and humanities sciences, generally accepted (Zikmund, 2000; Sekaran \& Bouge, 2009). The following table shows the results of the reliability of the study instrument.

Table 1. Cronbach Alpha coefficient

\begin{tabular}{llc}
\hline No. & Dimension & Alpha $(\alpha)$ Value \\
\hline 1 & staffing & 0.892 \\
$1-1$ & Recruitment & 0.892 \\
$1-2$ & Selection & 0.897 \\
2 & Excellence & 0.884 \\
& The Questionnaire as a Whole & 0.942 \\
\hline
\end{tabular}

The table illustrates the reliability values of the main research variables. Cronbach Alpha indicators show that the research instruments, in general, enjoys a high reliability degree and ability to achieve the study objectives.

\section{Results}

\subsection{Study Sample Characteristics}

The frequencies and percentages were obtained to describe the study sample characteristics; the results of the demographic variables of the study sample were summarized (age, academic degree, years of experience, position), which are shown in the following Table 2.

Table 2. Distribution of the study sample by the demographic variables

\begin{tabular}{|c|c|c|c|}
\hline Variable & Category & Frequency & Percentage $(\%)$ \\
\hline & Less than 30 years & 61 & 29 \\
\hline \multirow[t]{3}{*}{ Age } & $30-35$ years & 58 & 27 \\
\hline & $35-39$ years & 53 & 26 \\
\hline & 40 years and more & 39 & 18 \\
\hline \multirow[t]{2}{*}{ Total } & & 211 & 100 \\
\hline & Diploma & 23 & 11 \\
\hline \multirow[t]{3}{*}{ Academic Degree } & BA & 118 & 56 \\
\hline & MA & 63 & 30 \\
\hline & Ph.D. & 7 & 3 \\
\hline \multirow[t]{2}{*}{ Total } & & 211 & 100 \\
\hline & 5 years and less & 24 & 12 \\
\hline \multirow[t]{3}{*}{ Years of Experience } & $6-10$ years & 60 & 28 \\
\hline & $11-15$ years & 76 & 36 \\
\hline & 16 years and more & 51 & 34 \\
\hline Total & & 211 & 100 \\
\hline \multirow[t]{2}{*}{ Position } & Principal & 41 & 19 \\
\hline & Head of Department & 170 & 81 \\
\hline Total & & 211 & 100 \\
\hline
\end{tabular}

The Table indicates that $29 \%$ of the study sample are those whose ages are less than 30 years; $27 \%$ between 30 and 40 years, 26\% are between 35-39 years, and finally, the percentage of the unit of analysis ages are 40 years and more $81 \%$. As for the academic degree, as well illustrated in the table, $11 \%$ of the study sample hold intermediate diplomas in their majors, $56 \%$ hold BA degrees in their specializations, $30 \%$ hold the MA degree, 
and finally $3 \%$ are those who hold Ph.D. Degrees in their specializations. In the years of experience variable, the results already shown in the table indicated that $12 \%$ have 5 years and less of experience, $28 \%$ fall in the category 6-10 years, $36 \%$ of those who have experiences from 11 to 15 years, and finally $24 \%$ of the surveyed have 16 years and more of experience. Finally, as for the position, the same table shows that $19 \%$ are principals and $81 \%$ are heads of department.

\subsection{Descriptive Statistic}

\subsubsection{Recruitment and Selection}

To describe the importance level of recruitment and selection functions in the private schools, the researcher used the means, standard deviations as shown in the following Table 3:

Table 3. Means, SD's and importance level of recruitment and selection functions

\begin{tabular}{|c|c|c|c|c|c|}
\hline Order & Item & M & SD & Rank & Level of Importance \\
\hline 1 & $\begin{array}{l}\text { The school depends on promotion to obtain the workforce from within } \\
\text { the school to fill the vacant position }\end{array}$ & 4.15 & 0.85 & 1 & High \\
\hline 2 & $\begin{array}{l}\text { The school depends on the private sector recruitment office and } \\
\text { companies to obtain its workforce. }\end{array}$ & 3.81 & 0.91 & 7 & High \\
\hline 3 & The school depends on the university graduates to obtain its workforce. & 3.87 & 0.80 & 3 & High \\
\hline 4 & The school depends on websites advertising to obtain its workforce. & 3.76 & 0.89 & 8 & High \\
\hline 5 & $\begin{array}{l}\text { The school depends on advertising in the daily newspapers to obtain its } \\
\text { workforce. }\end{array}$ & 3.96 & 0.79 & 2 & High \\
\hline 6 & $\begin{array}{l}\text { Job applications are checked and made sure that they meet the general } \\
\text { requirement of the job before receiving from applicants. }\end{array}$ & 3.83 & 0.74 & 6 & High \\
\hline 7 & $\begin{array}{l}\text { The evidential papers and documents enclosed with the applications are } \\
\text { well checked and their validity is ensured. }\end{array}$ & 3.84 & 0.83 & 5 & High \\
\hline 8 & $\begin{array}{l}\text { The applicants pass a number of tests including knowledge } \\
\text { examinations. }\end{array}$ & 3.62 & 0.87 & 12 & Median \\
\hline 9 & The examinations are in writing. & 3.87 & 0.83 & 3 & High \\
\hline 10 & The examinations are practical. & 3.44 & 0.99 & 14 & Median \\
\hline 11 & $\begin{array}{l}\text { The examinations prepared by the test committee measure the technical } \\
\text { skills of the applicant effectively and efficiently. }\end{array}$ & 3.64 & 0.98 & 10 & Median \\
\hline 12 & Special forms are already used by the interviewing committee. & 3.85 & 0.90 & 4 & High \\
\hline 13 & The time allocated for the interviews is insufficient & 3.75 & 0.74 & 9 & High \\
\hline 14 & The interview location is well prepared. & 3.44 & 0.94 & 13 & Median \\
\hline \multirow[t]{2}{*}{15} & Practical experience is one of the selection criteria for the applicants. & 3.63 & 0.93 & 11 & Median \\
\hline & The general mean $(\mathrm{M})$ and SD of the recruitment and selection. & 3.76 & 0.91 & & \\
\hline
\end{tabular}

The table explains the responses of the study samples on the items concerning recruitment and selection where, the means ranged between these items (4.15-3.44). In the first rank was the item "The school depends on promotion to obtain the workforce from within the school to fill the vacant position", with a M (4.15), which is higher than the general M (3.76), and with a (0.85) SD. Meanwhile, the item "The examinations are practical." came fourteenth and last, with a M (3.44) below the general M (3.76), and a (0.99) SD. The table further illustrates low dispersion in the sample's responses about recruitment and selection variables, which reflect agreements between the sample views.

\subsubsection{Institutional Excellence}

To describe, the importance level of the institutional excellence in the surveyed private schools, the researcher used the means, standard deviations, as shown in the following Table 4. 
Table 4. Means, SD's and importance level of institutional excellence

\begin{tabular}{|c|c|c|c|c|c|}
\hline Order & Item & M & SD & Rank & Level of Importance \\
\hline 1 & $\begin{array}{l}\text { The school carries out continuous survey to identify the students' various } \\
\text { needs. }\end{array}$ & 3.88 & 0.78 & 4 & High \\
\hline 2 & $\begin{array}{l}\text { The processes of providing students' various supporting services are } \\
\text { subject to control and continuous improvement. }\end{array}$ & 4.12 & 0.76 & 1 & High \\
\hline 3 & $\begin{array}{l}\text { The school uses modern technological methods in providing its services } \\
\text { and educational program. }\end{array}$ & 3.76 & 0.69 & 2 & High \\
\hline 4 & The supporting services are characterized by speed and comfort. & 3.51 & 0.87 & 5 & Medium \\
\hline 5 & $\begin{array}{l}\text { The school continuously monitors its facilities to improve the methods of } \\
\text { providing the educational services. }\end{array}$ & 3.73 & 1.04 & 3 & High \\
\hline & General $\mathrm{M}$ and SD of the Excellence & 3.74 & 0.88 & & \\
\hline
\end{tabular}

The table explains the responses of the study samples on the items concerning institutional excellence where, the means ranged between these items (3.51-4.12). In the first rank was the item "The processes of providing students' various supporting services are subject to control and continuous improvement", with a M (4.12), which is higher than the general M (3.74), and with a (0.76) SD. Meanwhile, the item "The supporting services are characterized by speed and comfort" came fifth and last, with a M (3.51) below the general M, and a (0.87) SD. The table further indicates the low dispersion in the sample's responses about the institutional excellence variable, which reflects agreements between the views of the study sample.

\subsection{Hypotheses Testing}

The following decision rule was relied upon in testing the hypotheses: The null hypothesis $(\mathrm{H} 0)$ is accepted if the significance value was higher than $5 \%$, and it will be rejected if the significance value is less than the 5\%.

\subsubsection{Main Hypothesis H01}

There is no statistically significant effect of the recruitment and selection functions in achieving the institutional excellence at $(\alpha \leq 0.05)$ significance level. Of this main hypothesis, the following sub-hypotheses were derived:

To test this main hypothesis, the multiple regression analysis was used, results are illustrated in the following Table 5.

Table 5. Results of the multiple regression to test the effect of recruitment and selection functions in achieving the institutional excellence

\begin{tabular}{llcccccc}
\hline Dependent Variable & Variables & $\mathrm{R}$ & $\mathrm{R} 2$ & $\mathrm{~F}$ & $\mathrm{R}^{2}$ Changed & F changed & Sig \\
\hline The Institutional Excellence & Recruitment & 0.741 & 0.519 & 263.316 & 0.58 & 263.316 & 0.000 \\
& Selection & 0.767 & 0.568 & 162.968 & 0.078 & 43.383 & 0.000 \\
\hline
\end{tabular}

The results of the statistical analysis showed in Table 5 a statistically significant effect of the recruitment and selection functions in achieving the institutional excellence, as the correlation coefficient $\mathrm{R}$ of the recruitment function was (0.741) and for selection, it was (0.767). As for $\mathrm{R}^{2}$ coefficient, it amounted (0.519) for recruitment and $(0.568)$ for selection. The value of the change in the determination coefficient $\mathrm{R}^{2}$ amounted $(0.58)$ for recruitment, and (0.078) for selection. The significance of this effect is assured in $F$ value which amounted (236.316) for recruitment and (162.968) for selection; and it was significant at $(\alpha \leq 0.05)$ significance level. This, in turn, confirms the invalidity of accepting the first main hypothesis. Accordingly, the first null hypothesis is rejected, meanwhile the alternative hypothesis is accepted, which is as follows: There is statistically significant effect of the recruitment and selection functions in achieving the institutional excellence

\subsubsection{Sub Hypotheses Testing}

For testing the effect of each of the recruitment and selection function in the institutional excellence the researcher divided the first main hypothesis into two sub-hypotheses as follows:

The First Sub-hypothesis H01-1 
There is no statistically significant effect of the recruitment function in achieving the institutional excellence at $(\alpha \leq 0.05)$ significance level.

For the purpose of testing this hypothesis, the researcher used the simple regression analysis, the results are shown in the following Table 6.

Table 6. Results of simple regression to test the effect of recruitment function in achieving the institutional excellence

\begin{tabular}{lccccc}
\hline Dependent Variable & $\mathrm{R}$ & $\mathrm{R}^{2}$ & $\mathrm{~F}$ & $\beta$ & $\mathrm{Sig}$ \\
\hline The Institutional Excellence & 0.661 & 0.436 & 106.073 & 0.681 & 0.000 \\
\hline
\end{tabular}

The statistical analysis results in Table 6 showed a statistically significant effect of the recruitment function in achieving the institutional excellence. The correlation coefficient $\mathrm{R}$ amounted $(0.661)$; meanwhile $\mathrm{R}^{2}$ coefficient amounted (0.436), meaning that (0.436) of the changes in achieving the institutional excellence is resulting from the change in the level of attention to the recruitment process. On the other hand, the effect degree $\beta$ value was (0.681), which means that the increase of one degree in the attention level to the recruitment process leads to an increase in the level for achieving the institutional excellence by (0.681). However, the significance of this change is further ensured by the value of the computed F (106.073), which is statistically significant at $(\alpha \leq 0.05)$ level. This confirms the invalidity of the accepting the first sub-hypotheses. Accordingly, the null hypothesis is rejected and the alternate hypothesis is accepted which states as follow: There is statistically significant effect of recruitment function in achieving the institutional excellence.

The Second Sub-hypothesis H01-2

There is no statistically significant effect of the selection function in achieving the institutional excellence, at ( $\alpha$ $\leq 0.05$ ) significance level.

For testing this hypothesis, the researcher used the simple regression analysis, the results are shown in the following Table 7.

Table 7. Results of the simple regression to test the effect of the selection function in achieving the institutional excellence

\begin{tabular}{lccccc}
\hline Dependent Variable & $\mathrm{R}$ & $\mathrm{R}^{2}$ & $\mathrm{~F}$ & $\beta$ & Sig. \\
\hline The Institutional Excellence & 0.680 & 0.492 & 117.556 & 0.586 & 0.000 \\
\hline
\end{tabular}

The statistical analysis results in Table 7 explained a statistically significant effect of the selection function in achieving the institutional excellence. The correlation coefficient $\mathrm{R}$ amounted $(0.680)$, meanwhile $\mathrm{R}^{2}$ coefficient amounted (0.492), meaning that (0.492) of the changes in achieving the institutional excellence is resulting from the change in the level of attention to the selection function. On the other hand, the effect degree $\beta$ value was (0.586), which means that the increase of one degree in the attention level to the selection function leads to an increase in the level for achieving the institutional excellence by (0.586). However, the significance of this change is further ensured by the value of the computed $\mathrm{F}(117.556)$. This confirms the invalidity of the accepting the second sub-hypotheses. Accordingly, the null hypothesis is rejected and the alternate hypothesis is accepted which states as follows: There is statistically significant effect of the selection function in achieving the institutional excellence.

\section{Conclusions}

Based on the results analysis the following conclusions and recommendations can be made that may serve the owners and principles of the private schools in Jordan:

The recruitment and selection importance level in the private schools was high as viewed by the sample of the research population.

The results showed that the importance level of the institutional excellence in the private schools was high as viewed by the sample of the research population.

There is a statistically significant effect of recruitment and selection functions in achieving the institutional 
excellence at (0.05) significance level in the private schools. This study is in agreement with that of Al-Jareery (2001), which indicated an effect of the human resources strategy, and selection strategy in achieving the competitiveness advantages. It is also in line with the study of Hasan (2009), which indicated the existence of a statistical significance of both human resources recruitment and human resources selection on achieving both of the cost and innovation advantages.

\section{Recommendations and Suggested Future Studies}

After reaching and analyzing the results, the researcher would like to offer the following recommendations for achieving the institutional excellence in the private schools subject matter of this research, most importantly:

It is quite essential for the school administration to follow-up the wages competitiveness; as in certain cases, low wages may lead to the resignation of the efficient workforce in these schools, which, in turn, will weaken its ability to achieve the institutional excellence requirements.

Additional fringe benefits, such as medical insurance, may contribute to attract efficient employees and retain them for longer times. However, the increasing percentage of the total costs of such benefits drives the management to administer these benefits in a well planned manner.

It is recommend to pay attention for providing special services to the female workers, and provide stability factors at work, such as nursery for their children till the preschool age, for a discounted price; or even free as incentive, if possible. This will contribute to recruit the best and most stable competencies, which will be positively reflected on improving the performance level and achieving the institutional excellence.

It is recommend paying great attention to the recruitment and selection procedures, and its requirements to ensure the personal abilities and tendencies of the applicants. It is also recommend obtaining a pledge by the school administration from the applicant that he/she will not leave work before the end of the school year; and that the distinguished performance incentive should be connected to remaining in the same school.

Conducting a study to underline the mediating role of the job satisfaction on the relationship between the recruitment and selection and achieving the institutional excellence in different service or manufacturing sectors, which may help in enhancing the generalization of the results.

\section{References}

Abdulbaqi, S. (2001). The scientific and practical aspects of human resource management in organizations (2nd ed.). Amman: Dar Wael for Publication and Distribution.

Aldallal, M. (2005). Performance evaluation using self assessment approach and EFQM excellence model: The case of Abu Dhabi police college (unpublished Master Degree). University of Bradford, United Kingdom.

Al-Salmi, A. (2001). Human Resources Management (1st ed.). Amman: Dar Al-Safaa for Distribution and Publishing.

Al-Sayyid, R. (2007). Excellence habits of the individuals with higher management skills. Cairo: United Arab Company for Marketing and Imports.

Aqli, A. S. (2005). Management of the contemporary human resources: A strategic dimension. Amman: Dar Wa'el for publication and distribution.

Campion, S. M. A. (1991). Meaning and measurement in turnover, comparison of alternative measures and recommendations for research. Journal of Applied Psychology, 76, 199-212. http://dx.doi.org/10.5829/idosi.mejsr.2013.16.11.12044

Collins, C., \& Clark, K. D. (2003). Strategic human resource practices, top management, team social networks, and firm performance: The role of human resource practices in creating organizational competitive advantage. Academy of Management Journal, 46(6), 740-751. http://dx.doi.org/10.2307/30040665

DeCenzo, D. A., \& Robbins, S. P. (2005). Fundamentals of human resource management (8th ed.). John Wiley \& Song, Inc.

DeNisi, A. S., \& Griffin, R. W. (2001). Human resource management (2nd ed.). Houghton Mifflin Company.

Dissler, G. (2003). Human resource management (9th ed.). New Jersey: Prentice- Hall.

Hair, J., Black, W., Babin, B., Anderson, R., \& Tatham, R. (2006). Multivariate Data Analysis (6th ed.). Pearson Prentice Hall.

Hassan, F. H. (2009). The staffing strategy of human resources and its impact on the achievement of competitive advantage: An empirical study in the Jordanian telecommunications sector (Unpublished Master Thesis). 
University of the Middle East University, Amman, Jordan.

Hulin, C. L., Roznowski, M., \& Hachiya, D. (1985). Alternative opportunities and withdrawal decisions: Empirical and theoretical discrepancies and an integration. Psychological Bulletin, 97, 233-250. http://dx.doi.org/10.1037/0033-2909.97.2.233

Jariri, S. O. (2001). The impact of selecting personnel in achieving competitive advantages strategy: An empirical study in Iraqi banks sample (Unpublished Master Thesis). School of Management and Economics, Mustansiriya University, Baghdad.

Jawad, S. N., \& Al-Jraisheh, Y. (2008). The leadership skills and their role in adopting the excellence strategy: An analytic study in the Jordanian banks. Presented to the First Arab Conference-Sustenance of the Excellence and Competitiveness in the Public and Private Sectors' Institutions, Arab Administrative Development Organization, Amman.

Naimi, M. A., \& Sweiss, R. J. (2008). Achieving precision in quality management: Concepts and practices. Amman: Dar Yazouri for Publication and Distribution.

O'Reilly, C. A., Chatman, J., \& Caldwell, D. F. (1991). People and organizational culture: A profile comparison approach to assessing person organization fit. Academy of Management Journal, 34, 487-516. http://dx.doi.org/10.2307/256404

Salem, M. S., \& Harfouch, A. (2002). Human resource management: A strategic approach. Irbid: The Modern World of Books for Publication and Distribution.

Schervish, P. G. (1983). The structural determinants of unemployment, vulnerability and power in market relations (pp. 71-112). New York, NY: Academic Press.

Sekaran, U. (2003). Research methods for business. John Wiley \& Sons.

Steel, R. P., \& Ovalle, N. K. (1984). A review and meta-analysis of research on the relationship between behavioral intentions and employee turnover. Journal of Applied Psychology, 69, 673-86. http://dx.doi.org/10.1037/0021-9010.69.4.673

Thompson, A. A., Strickland, A. J., \& Gamble, J. E. (2006). Crafting and executing strategy, the quest for competitive advantage concepts and cases (15th ed.). Boston: McGraw-Hill Irwin.

Zairi, M. (2005). Excellence toolkit: Delivering sustainable performance. Publishing TQM College, e-TQM College, Dubai.

Zikmund, W. G. (2000). Business research methodology (6th ed.). Harcourt College Publisher.

\section{Copyrights}

Copyright for this article is retained by the author(s), with first publication rights granted to the journal.

This is an open-access article distributed under the terms and conditions of the Creative Commons Attribution license (http://creativecommons.org/licenses/by/3.0/). 